\title{
HUBUNGAN RELIGIUSITAS DENGAN KECEMASAN MENGHADAPI PARTUS PADA IBU NULLIPARA DI WILAYAH KERJA PUSKESMAS PARONGPONG KABUPATEN BANDUNG BARAT
}

\author{
RELIGIUSITY RELATIONSHIP WITH ANXIETY FACING PARTUS ON THE NULIPARA \\ MOTHER IN THE WORKING REGION PUSKESMAS PARONGPONG DISTRICT \\ BANDUNG BARAT
}

\author{
Tawarina Surbakti ${ }^{1}$, Gilny Aileen Joan², Denny Ricky ${ }^{3}$ \\ Fakultas IImu Keperawatan Universitas Advent Indonesia \\ Email: karorina@rocketmail.com
}

\begin{abstract}
ABSTRAK
Tujuan Umum dari penelitian ini adalah untuk melihat adanya hubungan religiusitas dengan kecemasan menghadapi partus pada ibu nullipara diwilayah kerja Puskesmas Parongpong Kabupaten Bandung Barat. Teknik analisis data untuk penelitian ini adalah metode deskriptif. Dengan 15 responden ibu hamil anak pertama yang usia kandungan 7-9 bulan dan beragama muslim. Hasil yang diperoleh adalah thitung = $1,442<$ ttabel $=-2,160$ berarti Ho diterima dan Ha ditolak dapat disimpulkan bahwa terdapat hubungan yang signifikan antara religiusitas dengan kecemasan dalam mengahadapi partus dengan kuat hubungan yang rendah. Hasil ini disebabkan oleh faktor lain antara kurangnya dukungan keluarga terutama suami dan kurangnya keuangan keluarga.
\end{abstract}

Kata Kunci: Pengaruh religiusitas dengan kecemasan menghadapi partus.

\section{ABSTRACT}

The General from this research is to see the relationship religiusitas with anxiety at parturition in nullipara in the territory of the Community Parongpong of the Bandung regency. The data analysis for this study is the method of descriptive. With 15 of pregnant women the first boy to the age of 7-9 months and is a Muslim. The result obtained is thitung -- of 1,442 < ttabel -- of 2,160 that Ho and Ha been rejected can be concluded that there is a significant connection between religiusitas with anxiety in facing parturition with a strong relationship. The result is caused by other factors between the lack of family support especially the husband and a lack of family finances.

Keywords: The influence of religiosity with anxiety Facing parturition . 


\section{PENDAHULUAN}

Manusia adalah kesatuan yang holistik, dimana manusia terdiri dari tubuh, jiwa, dan roh. Menurut Sawang (2011) bahwa manusia tidak bisa lepas dari manusia lain, demikian pula dengan lingkungan fisik atau alam sekitarnya. Manusia juga tergantung kepada Tuhan yang Maha Kuasa selaku pencipta dan penentu hidupnya.

Dalam artikel yang ditulis oleh Doni (2013) yang dikutip melalui buku Hubungan Iman Kristen dengan Kesehatan Tubuh menyatakan bahwa penelitian yang dilakukan di Amerika telah lama mengetahui kekuatan penyembuhan melalui iman dan doa. Faktanya, 82 persen orang Amarika percaya pada kekuatan penyembuhan melalui doa, 64 persen berpikir dokter harus berdoa kepada pasien yang memintanya. 99 persen dokter di Amerika mengatakan bahwa kehidupan iman dapat berkontribusi positif pada proses penyembuhan. Akan tetapi sering kali tenaga kesehatan melupakan pentingnya berdoa dalam setiap tindakan pelayanan demi kesembuhan pasien, menyebabkan pasien mengalami kecemasan, ketakutan dan merasa beban penderitaanya bertambah.

Manusia dalam mengatasi kecemasan menggunakan upaya dengan cara mengubah pola pikir (kognitif), sehingga akan merubah perilaku. Cara mengatasi kecemasan ini sangat dipengaruhi oleh lingkungan sekitar dan dari dalam diri seseorang tersebut. Faktor lingkungan sekitar seperti, keluarga, teman, sosial dia berada, dan juga agama sebagai kepercayaan yang dianutnya akan sangat mempengaruhi diri seseorang dalam mengatasi kecemasan. Menurut Agustinus (2011) ada beberapa hal yang dapat dilakukan oleh lbu saat dirinya mengalami kecemasan yaitu : kontrol pernafasan yang baik, melakukan relaksasi, intervensi kognitif, pendekatan agama,dukungan keluarga, olahraga.

Dalam Kamus Besar Bahasa Indonesia menerangkan bahwa Agama adalah suatu ajaran, sistem yang mengatur tata keimanan (kepercayaan) dan peribadatan kepada Tuhan yang maha esa. Pada saat seseorang memiliki tingkat keagamaan atau religiusitas yang tinggi maka akan semakin tinggi jugalah tingkat kepercayaan seseorang tersebut terhadap Tuhannya, dan sebaliknya semakin rendah tingkat keagamaan atau religiusitas seseorang maka akan semakin rendah juga tingkat kepercayaan seseorang tersebut terhadap Tuhannya. Dalam setiap Agama cara berhubungan atau berkomunikasi dengan Tuhannya adalah dengan cara berdoa. Dalam Kamus Besar Bahasa Indonesia dituliskan Doa adalah permohonan (harapan, permintaan, pujian) kepada Tuhan. Dengan manusia berdoa dan percaya kepada Tuhan maka akan ada motivasi yang akan muncul dalam diri manusia. Motivasi tersebut akan menjadi suatu harapan dan penyerahan kepada Tuhan yang maha esa akan kesembuhan pada dirinya.

Menurut Departemen Kesehatan (2012) angka kematian ibu (AKI) di Indonesia terus mengalami penurunan. Secara garis besar angka kematian Ibu (AKI) di Indonesia masih tinggi walaupun sudah terjadi penurunan dari 307/100.000 kelahiran hidup pada Survei Demografi dan Kesehatan Indonesia/SDKI 2010/2011 menjadi 216/100.000 kelahiran hidup. "Pada tahun 2011 laporan Balai Pengobatan Swasta (BPS) menyebutkan AKI menjadi 216/100.000 kelahiran, Dibanding dengan angka kematian ibu di negara tetangga, seperti Thailand, Malaysia, dan Singapura, maka Indonesia memang masih cukup jauh tertinggal, karena Singapura sudah 6/100.000 dan angka itu boleh dikatakan sebagai suatu keadaan yang sangat ideal".

Menurut Suryani (2010) di Indonesia, sekitar 95\% tenaga kesehatan tidak terlalu memperhatikan kondisi psikis wanita melahirkan. Akan tetapi lebih memperhatikan kondisi fisik lbu dan bayi yang dilahirkan. Sehingga banyak wanita yang memilih persalinan dengan operasi 
atas dasar tidak ingin merasakan sakit pada proses persalinan.

Menurut Viebeck (2012) Kecemasan adalah perasaan takut yang tidak jelas dan tidak didukung oleh situasi. Kehamilan dapat merupakan sumber stressor kecemasan, terutama pada seorang lbu yang labil jiwanya. Disertai dengan keadaan psikologis, ketakutan, kecemasan dan spiritual akibat ketidakyakinan diri terhadap proses persalinan. Disinilah diperlukan peran tenaga kesehatan dalam menguatkan para Ibu yang akan bersalin. Dukungan yang diperoleh dari para tenaga kesehatan dapat membantu mengurangi kecemasan para lbu dalam bersalin, seperti mengajak Ibu berdoa bersama dan mendoakan agar bayi dan lbu lancar dalam persalinan.

\section{TINJAUAN PUSTAKA}

Dhrajat (dalam Cholifah, 2012) menjelaskan dengan memberikan ketenangan jiwa ibu hamil adalah salah satu peran penting yang dilakukan oleh agama. Penyakit fisik yang dialami seorang pasien membuat agama lebih mengutamakan proses mempercepat penyembuhan pasien dalam perawatan yang bersifat kejiwaan. Agama sanggup menolong orang untuk menerima kenyataan dan kekecewaan serta mendorong seseorang yang mengalami goncangan jiwa karena penyakit yang dideritanya, bila memohon pertolongan kepada Tuhan.

Menurut Dister (dalam Mahmudah, 2010) mempunyai hubungan baik dengan Tuhan dan tidak terasingi dari dirinya sendiri maupun dari Tuhan itu lah lbu hamil yang religius, karena baginya Tuhan segalanya penguasa dari nasib dan kematian sehingga lbu akan merasa tenang dalam menghadapi persalinan namun hal ini harus disertai dengan ajaran agama yang teratur dalam kehidupan sehari-hari. Sifat cenderung menyalahkan diri sendiri, merasa beban penderitanya bertambah dan ketakutan jika nanti bayi dikandungnya cacat secara jasmani dan rohani,itu lah yang dirasakan oleh lbu yang tidak memiliki hubungan yang baik pada Tuhan.
Menurut Hadi (dalam Cholifah, 2012) ketika akan menghadapi proses persalinan akan mengalami berbagai macam perasaan seperti tabah, takut, bingung, kesepian, dan putus asa. Bila seorang lbu memiliki kerohaniaan yang kuat tidak akan menyita pikirannya dengan hal rasa sakit yang dirasakannya karena baginya rasa sakit adalah hikmah yang disertai dengan kesembuhan dari Tuhan. Tapi bagi lbu yang tidak memiliki kerohaniaan akan selalu gelisah, ketakutan, gelisah setiap hari dan akan tampak parah dengan menyulitkan orang-orang yang menanganiuntuk merawatnya. Maka dengan demikian diperlukan religiusitas untuk mengurangi tingkat kecemasan lbu hamil dan juga memberikan dorongan moral dan spiritual.

Shodiq (2009) menyatakan rasa lelah ataupun emosi negative lainnya itu bisa menyebabkan konsentrasi selama persalinan. Untuk menjaga agar otak tetap fokus pada pikiran-pikiran dan gambarangambaran yang membantu proses kelahiran. Kecemasan yang timbul akibat dari perubahan-perubahan yang terjadi pada seorang Ibu hamil dalam menghadapi persalinan baik secara fisik maupun secara psikis.

Kecemasan Ibu hamil pada trimester III mempengaruhi psikologi dan emosional yang dikuasi oleh perasaan dan pikiran mengenai tanggung jawab sebagai lbu yang akan mengurus anaknya serta perasaan yang tidak menyenangkan yang mengancam individu seperti perubahan fisiologis seperti bentuk tubuh ataupun rahim yang semakin membesar dan perut menurun serta tekanan-tekanan yang dirasakan dalam perut yang menyebabkan ketidakstabilan kondisi psikologis (Kartono, 2007).

\section{METODE PENELITIAN}

Metode yang digunakan dalam penelitian ini adalah metode menurut Notoatmodjo (2012) metode deskriptif adalah suatu metode penelitian yang dilakukan dengan tujuan utama untuk membuat gambaran atau deskriptif tentang keadaan secara objektif 
(Sulistyaningsih, 2011). Sampel pada penelitian ini adalah Ibu nullipara trimester akhir usia kandungan 7-9 bulan beragama muslim di wilayah kerja puskesmas Parongpong Kabupaten Bandung Barat. Penelitian ini adalah purposive sampling. Sessudah responden mengisi 93 pernyataan kuesioner yang telah konten validity, kemudian dilakukan pengujian-pengujian yaitu : Uji Korelasi (R) menggunakan kolerasi Pearson Product Moment, uji Hipotesa adalah koefisien determinasi (R2), Rancangan uji hipotesis adalah uji signifikan dilakukan dengan mencari nilai $t$ hitung dengan t table untuk mencari nilai t hitung.

\section{HASIL}

Hasil penelitian Analisis Deskriptif Sesuai dengan Identifikasi masalah pertama : sejauhmana religiusitas pada ibu nullipara diwilayah kerja puskesmas parongpong kabupaten bandung barat?

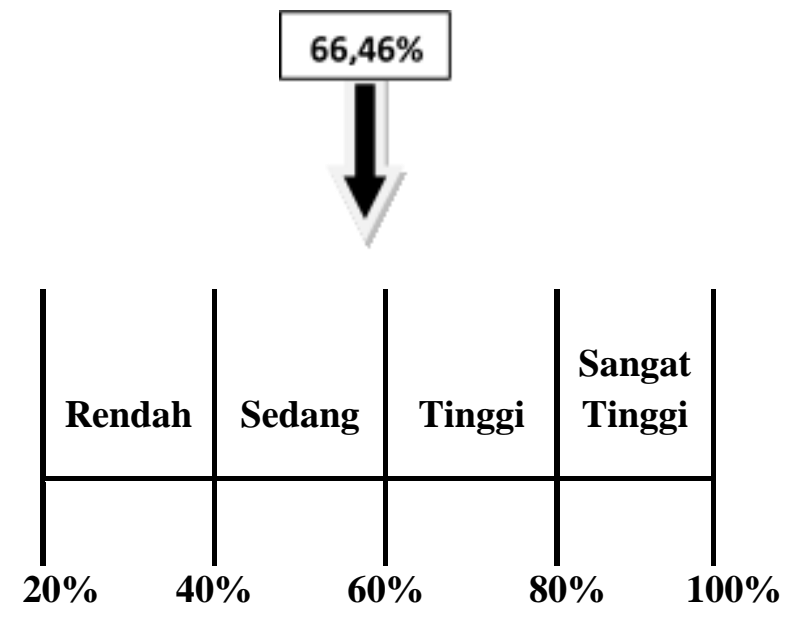

Hasil penelitian : Analisis Deskriptif Sesuai dengan Identifikasi masalah kedua : Sejauhmana Kecemasan menghadapi partus pada ibu nullipara diwilayah kerja puskesmas Parongpong Kabupaten Bandung Barat?

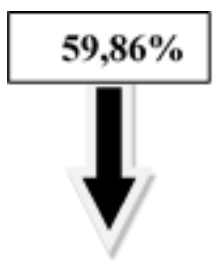

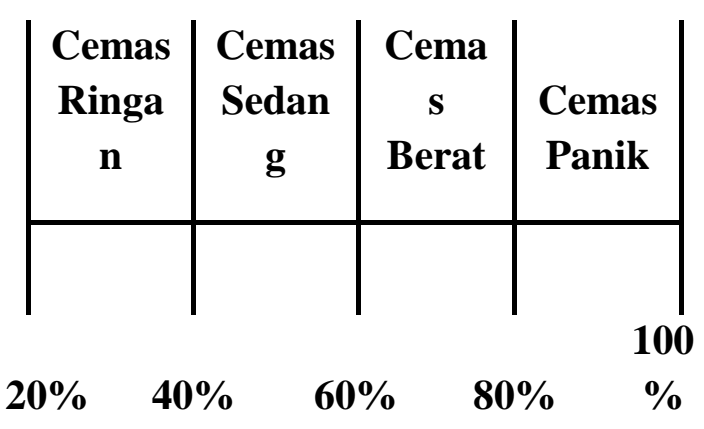

Hasil penelitian : Identifikasi masalah ketiga : Adakah hubungan antara religiusitas dengan kecemasan dalam menghadapi partus pada lbu nullipara diwilayah kerja puskesmas Parongpong Kabupaten Bandung Barat?

\begin{tabular}{|c|c|c|c|c|c|}
\hline $\begin{array}{l}\text { Hub } \\
\text { ung } \\
\text { an }\end{array}$ & $\begin{array}{l}\text { Koefisie } \\
\text { n } \\
\text { Korelasi } \\
\text { Pearson }\end{array}$ & $\begin{array}{c}\text { Kek } \\
\text { uata } \\
\mathrm{n} \\
\text { hub } \\
\text { ung } \\
\text { an }\end{array}$ & $\begin{array}{c}\mathrm{t} \\
\text { hit } \\
\text { un } \\
\mathrm{g}\end{array}$ & $\begin{array}{c}\mathrm{t} \\
\mathrm{tab} \\
\mathrm{el}\end{array}$ & $\begin{array}{c}\text { Kesi } \\
\text { mpul } \\
\text { an }\end{array}$ \\
\hline$X-Y$ & $-0,371$ & $\begin{array}{l}\text { Ren } \\
\text { dah }\end{array}$ & $\begin{array}{c}- \\
1,4 \\
42\end{array}$ & $\begin{array}{c}2,1 \\
60\end{array}$ & $\begin{array}{l}\text { Tida } \\
\mathrm{k} \\
\text { Signi } \\
\text { fikan }\end{array}$ \\
\hline
\end{tabular}

\section{PEMBAHASAN}

Pada variabel religiusitas pada ibu nullipara dengan jumlah item pertanyaan 48 butir dan jumlah responden 15 orang, diperoleh ratarata skor $66,46 \%$, Melalui rata-rata skor tanggapan dari 48 pertanyaan yang diajukan mengenai variabel religiusitas pada ibu nullipara, maka dapat diketahui bahwa tanggapan responden mengenai religiusitas pada ibu nullipara termasuk dalam kategori "Tinggi". Pada variabel kecemasan dalam menghadapi partus pada ibu nullipara dengan jumlah item pertanyaan 45 butir dan jumlah responden 15 orang, diperoleh ratarata skor $59,86 \%$. Melalui rata-rata skor tanggapan dari 45 pertanyaan yang diajukan 
mengenai variabel kecemasan dalam menghadapi partus pada ibu nullipara, maka dapat diketahui bahwa tanggapan responden mengenai kecemasan dalam menghadapi partus pada ibu nullipara termasuk dalam kategori "cemas sedang". Dikarenakan $t$ hitung $(-1,442)<t$ tabel $(-$ 2,160), maka HO diterima dan Ha ditolak, artinya terdapat hubungan yang tidak signifikan antara religiusitas dengan kecemasan dalam menghadapi partus dengan kuat hubungan yang rendah. Setelah diketahui adanya hubungan antara religiusitas dengan kecemasan dalam menghadapi partus dengan kuat hubungan yang rendah., maka besarnya hubungan antara religiusitas dengan kecemasan dalam menghadapi partus dengan kuat hubungan yang rendah. dapat diketahui melalui nilai koefisien determinasi.

$$
\begin{aligned}
& K D=R 2 \times 100 \% \\
& K D=(-0,371) 2 \times 100 \% \\
& =13,76 \%
\end{aligned}
$$

Dari rumus di atas dapat kita ketahui besarnya koefisien determinasi yaitu sebesar 13,76\%. Nilai ini menunjukkan bahwa sebesar $13,76 \%$ perubahanperubahan kecemasan dalam menghadapi partus terhadap responden disebabkan oleh religiusitas. Sedangkan sisanya sebesar $86,24 \%$ perubahan yang terjadi pada kecemasan dalam menghadapi partus disebabkan oleh faktor lain seperti kurangnya dukungan keluarga yang diberikan kepada ibu nullipara terutama dukungan dari suami dan kurangnya keuangan keluarga.

\section{KESIMPULAN}

Dari hasil analisa dan pengolahan data pada penelitian tentang hubungan antara eligiusitas dengan kecemasan dalam menghadapi partus pada ibu nullipara di wilayah puskesmas parongpong kabupaten bandung barat. maka penulis dapat mengambil kesimpulan sebagai berikut : Berdasarkan rata-rata skor tanggapan dari
48 pertanyaan yang diajukan mengenai variabel religiusitas pada ibu nullipara, maka dapat diketahui bahwa tanggapan responden mengenai religiusitas pada ibu nullipara termasuk dalam kategori "tinggi" Berdasarkan rata-rata skor tanggapan dari 45 pertanyaan yang diajukan mengenai variabel kecemasan dalam menghadapi partus pada ibu nullipara, maka dapat diketahui bahwa tanggapan responden mengenai Kecemasan dalam menghadapi partus pada ibu nullipara termasuk dalam kategori "cemas sedang". Terdapat hubungan yang tidak signifikan antara antara religiusitas dengan kecemasan dalam menghadapi partus dengan hubungan yang rendah dan kontribusi sebesar $13,76 \%$, hal ini di sebabkan karena faktor lain seperti kurangnya dukungan keluarga yang diberikan kepada ibu nullipara terutama dukungan dari suami.

Walaupun hasil penelitian ini tidak adanya hubungan yang signifikan diharapkan berguna bagi ibu hamil nullipara dan kelurga untuk mengatasi kecemasan pada saat menghadapi partus dengan meningkatkan religiusitas mereka dan berguna untuk melakukan penyuluhan kesehatan bagi ibuibu hamil anak pertama yang memiliki tingkat kecemasan yang tinggi agar dapat menanggulanginya dengan cara meningkatkan religiusitasnya

\section{DAFTAR PUSTAKA}

Agustinus., (2011). Anxiety Disorder. [INTERNET] .http://www.pikirdong.ac.id

Cholifah, S. (2012). Penghayatan Religiusitas Ibu Hamil Dalam Menghadapi Kecemasan Pra Persalinan.[SKRIPSI].Semarang.Fak ultas Ushuluddin.Institut Agama Islam Negeri Walisongo.Media

Purba, S. (2008). Manifestasi Kecemasan. Jakarta : Salemba Medika 
Shodiq, M, Mustika. (2009). Panduan spiritual kehamilan. Yogyakarta : Qudsi

Sugiyono, (2013). Statistika untuk penelitian. Bandung : Alfabeta

Sulistyaningsih. (2011). Metodologi Penelitian Kebidanan KuantitatifKualitatif. Edisi1l. Yogyakarta. Penerbit Graha IImu.

Suryani. (2010). Psikologi Ibu dan Anak.

Yogyakarta: Fitramaya.

Viebeck, S. (2012). Buku Ajar Keperawatan

Jiwa. EGC: Jakarta. 